\title{
Analysis of the cars lane changes accidents
}

\author{
Nicolae Ispas ${ }^{1 *}$, Mircea Năstăsoiu ${ }^{2}$ \\ ${ }^{1}$ Transilvania University of Brașov, inicu@unitbv.ro, Romania \\ ${ }^{2}$ Transilvania University of Brașov, m.nastasoiu@unitbv.ro, Romania
}

\begin{abstract}
Experimental cars crashes test are valuable tools for improve overall automotive safety. Lane change crashes (or more properly, the lane change family of crashes) are defined in this paper, in according with generally accepted sense when a car collides with a vehicle running on a neighboring band when the first leaves its lane. Such collision results from various vehicle maneuvers including typical lane change or others. For present paper, the main aim is to quantify the post lane changes collisions parameters for endorsed influences over possible more dangerous traffic accidents occurring. Other goal of the paper was the study of speeds differences over changes in cars initials trajectories.
\end{abstract}

\section{Introduction}

Lane change collisions occur when driving on motorways or on urban and/or interurban roads with two or more lanes on the same direction. Accidents of this type can have the more serious consequences as speed differences (relative speeds) between cars involved and impact angles are greater. Often collisions in the lane change occur when lane change the car traveling on the neighboring lane is in blind spot mirrors.

The paper's experimental results were obtained by support of DSD, Dr. Steffan Datentechnik GmbH - Linz, Austria in "Easter 2016 PC-Crash Seminar", using the same instrumentation as that described in: U.S. Department of Transportation, National Highway Traffic Safety Administration [1], N. Ispas and M. Năstăsoiu [2] and N. Ispas and M. Năstăsoiu [3] papers.

Four crash experiments were made for determination of velocities, accelerations and rotation of the cars involved in lane changes collisions using crashes design showed in the fig 1 to fig. 4 .

The main technical data of the cars used in the crashes experiments together with the cars shapes are presented in the same fig. 1 to fig. 4 .

Knowing that the cars weight and cars dimensions influences over post collision consequences we are uses motor vehicle with mass and dimensions "compatible" to avoidance. is inversely proportional to car mass or mass difference: in respect of Jan van der Sluis [4] "the heavier the car the lower the fatality or injury risk (and the higher the aggressiveness). Some authors also described the fact that in collisions between cars of equal mass, the outcome was better for heavier than for lighter cars".

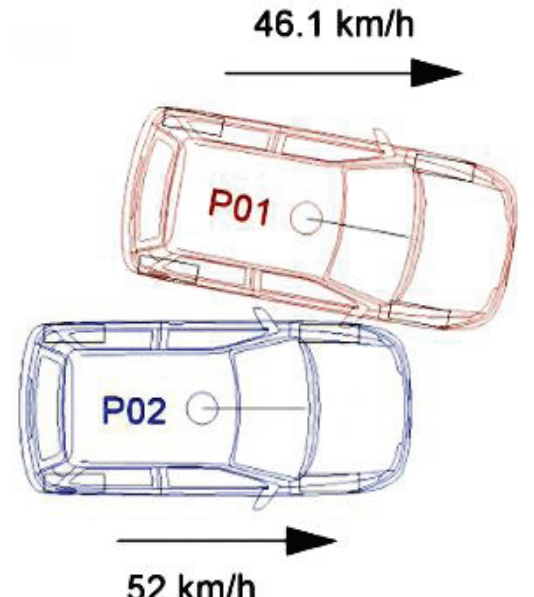

\begin{tabular}{|l|l|l|}
\hline & & \\
\hline
\end{tabular}

Fig. 1. First collision and cars involved characteristics in according with occurring tests

\footnotetext{
*Corresponding author: inicu@unitbv.ro
} 
Despite low difference in cars speed, in all collision cases the collision angle in near in blind spot mirrors.

In all four experimental tests, human cars drivers were uses.

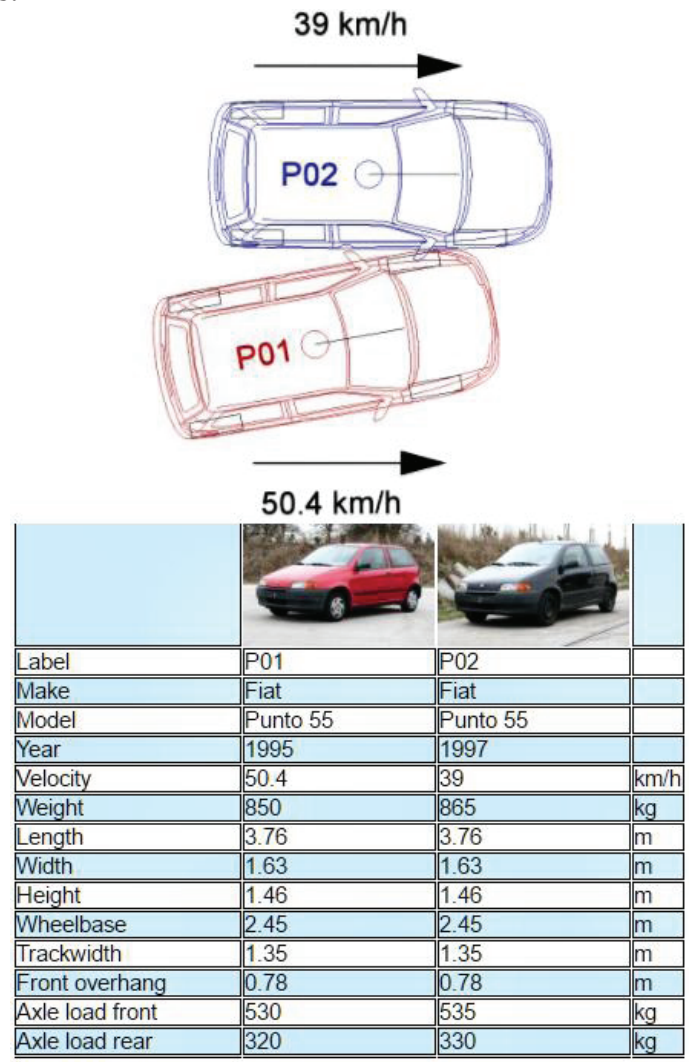

Fig.2. Second collision test and cars involved specifications.

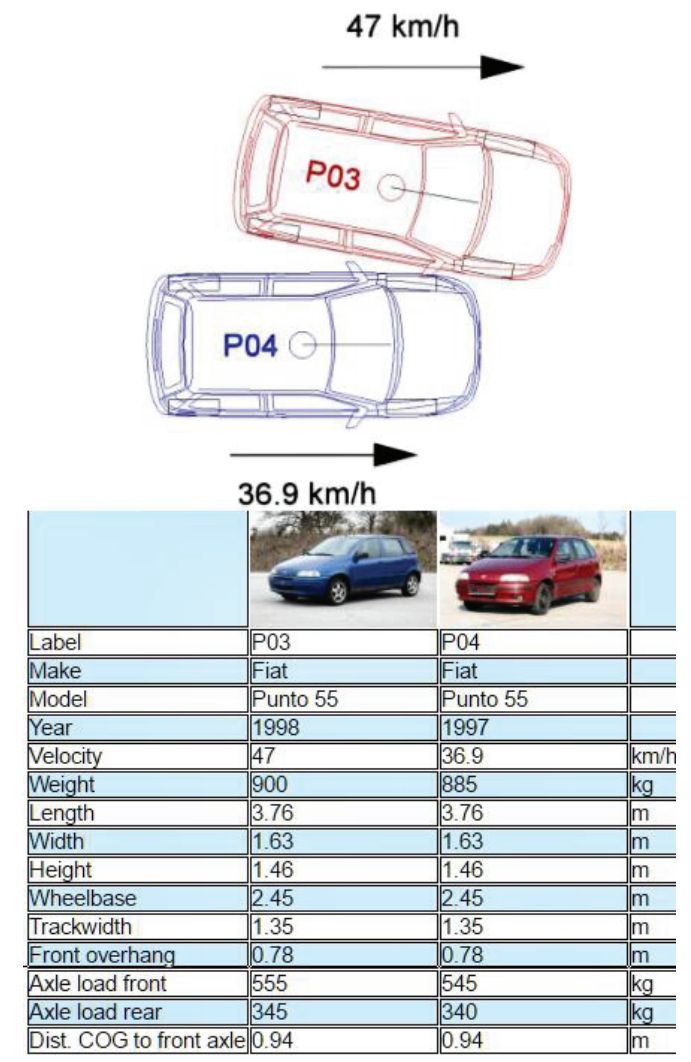

Fig.3. The third collision test and cars involved parameters.

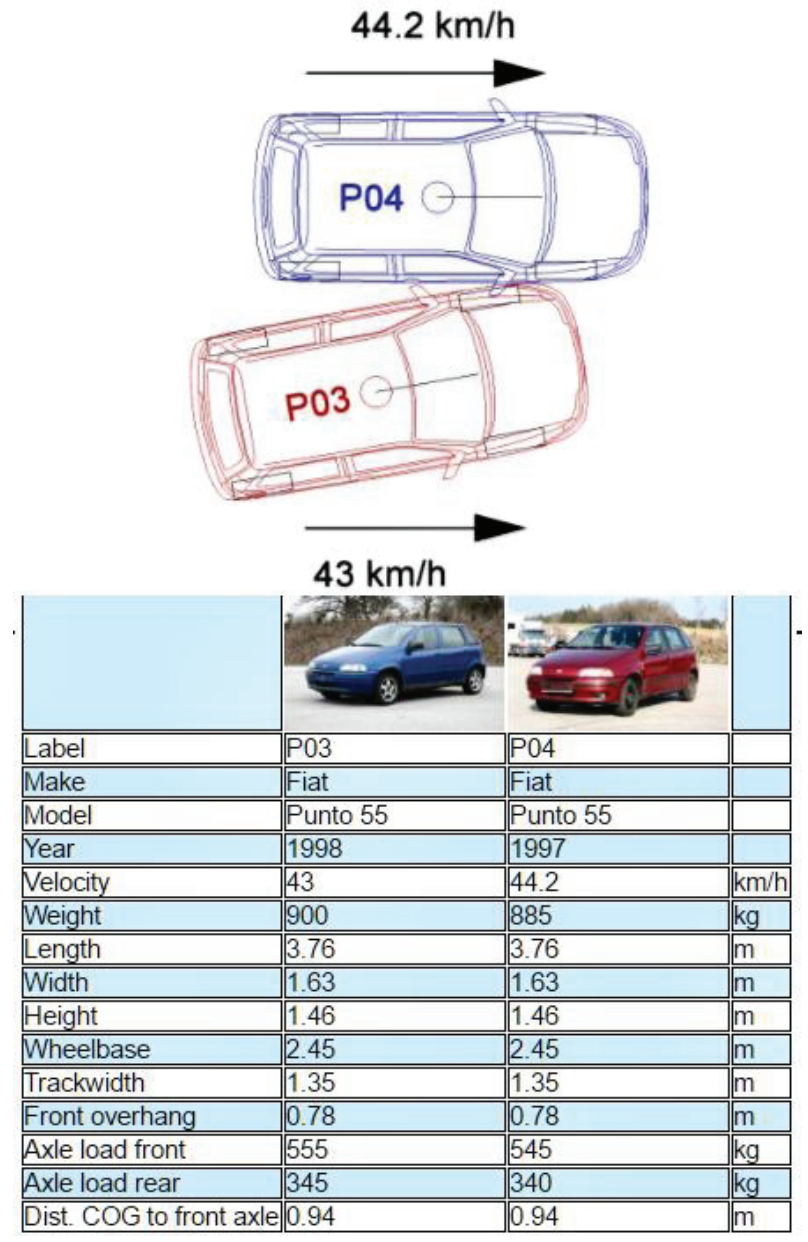

Fig.4. The fourth collision test and cars involved characteristics.

\section{Experimental results and discutions}

Four crash tests were performed according with EN1317 and EN12767. In each of them were use human's car drivers in both in crash cars. Complex accelerometers were mounted in the Center of Gravity (CG) of each cars

Velocities, speeds (by GPS), accelerations and rotations of the cars were also measured.

For quantify the influences over the cars after lane change collision, we used valuable data obtained from real world experimental crashes.

All attempts have been made so that the speeds of the vehicles involved can be considered relative, and the experimental research scenarios, in all four cases, can be assimilated to accidents on the highway when changing the lane.

Assimilating the collisions of the four cases with those produced on the highway when changing the lane, it can be considered that the speeds of the cars involved are ordered in increasing order, starting from the cars that run on the first right lane.

This kind of test data enable the possibilities to analyze influences of collisions caused by lane changes on subsequent, often more dramatic accidents.

\footnotetext{
*Corresponding author: inicu@unitbv.ro
} 


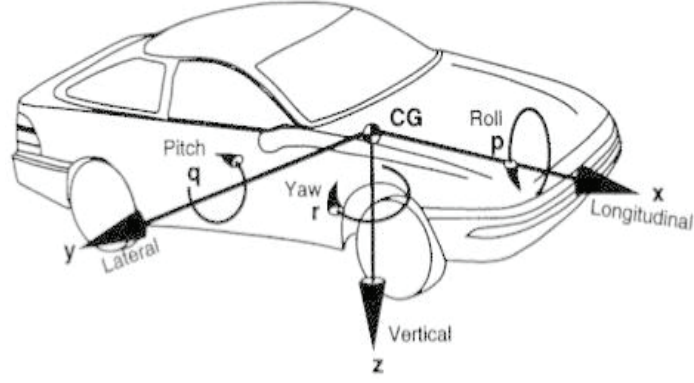

Fig.5. The automotive coordinate system used for experimental tests.

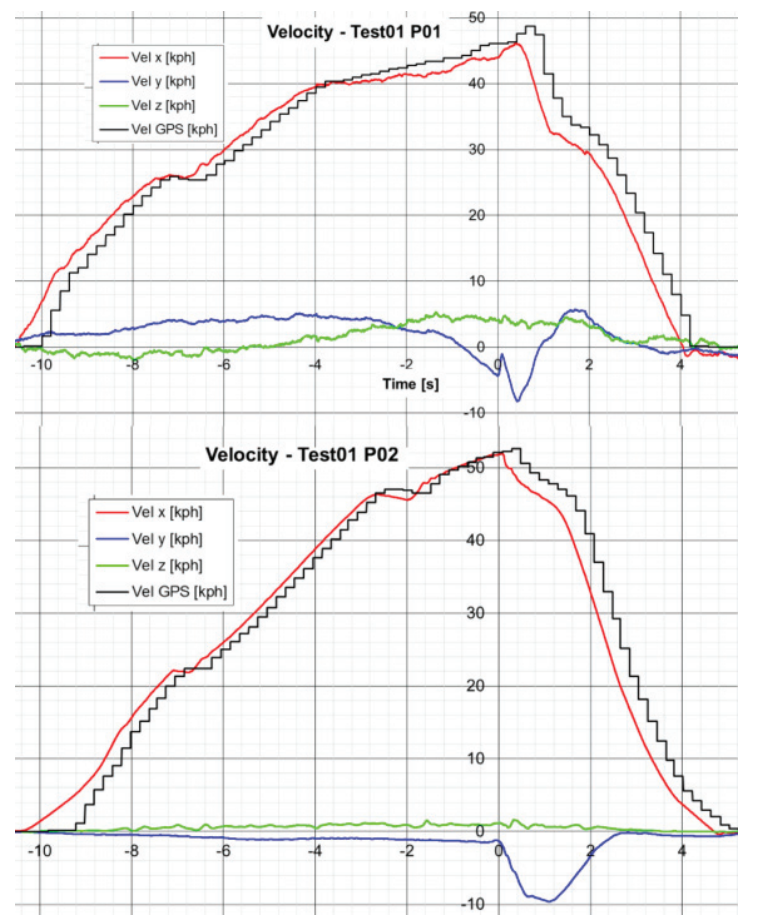

Fig.6. Velocities and GPS speeds of the cars involved in collision test

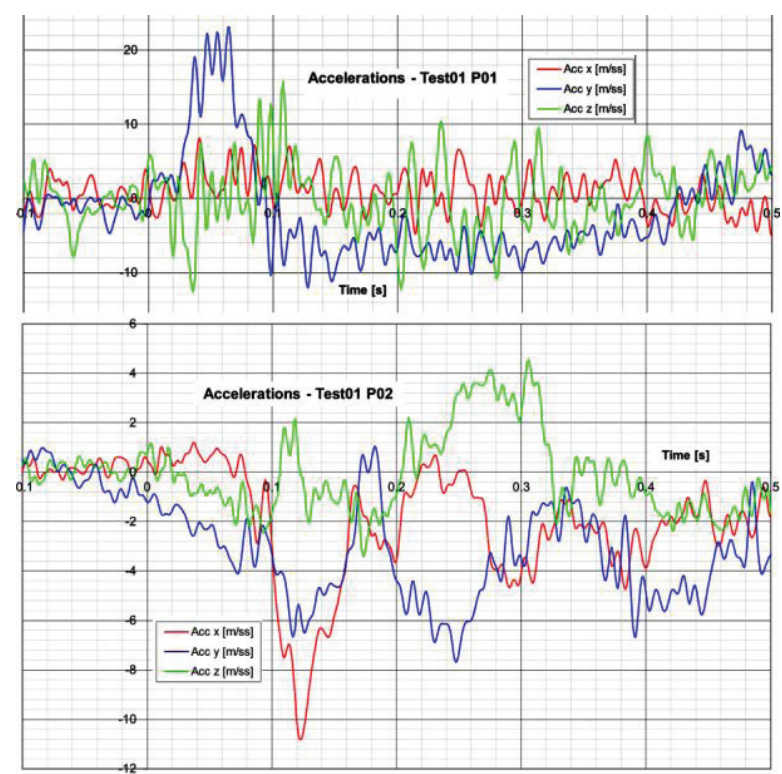

Fig.7. Accelerations of the cars involved in first collision test

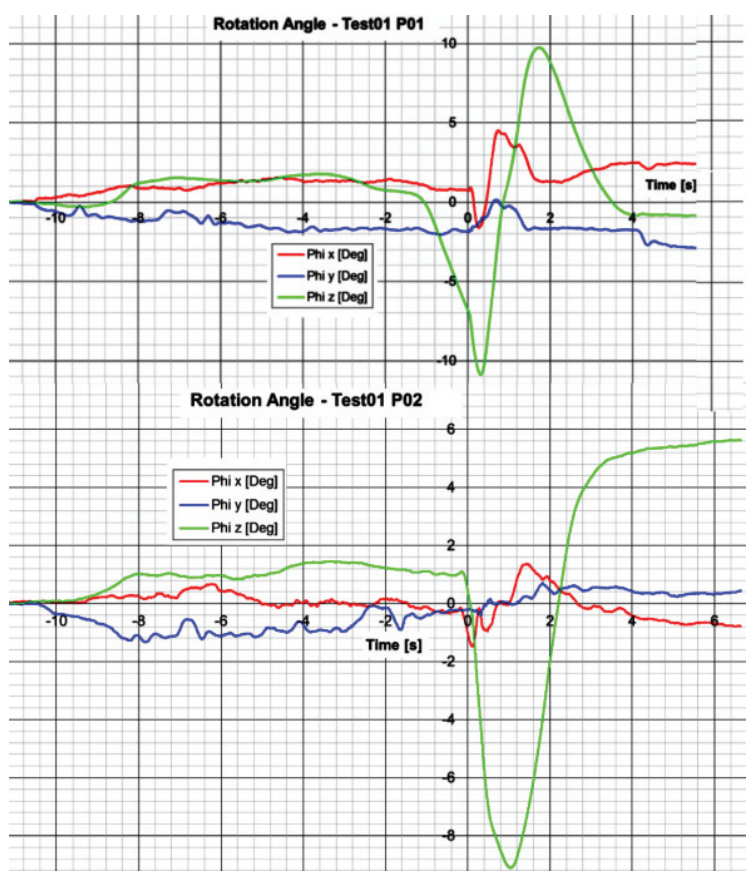

Fig.8. Rotation angles of the cars involved in first collision test.

In the fig. 5 shows the coordinate system of the vehicle in relation to which the velocities, accelerations and angles of rotation have been determined in all four test cases.

Fig. 6 to 17 show the variations in the velocities, speeds, accelerations and rotation angles of the cars involved in the four cases of lane-change collisions described in the previous chapter.

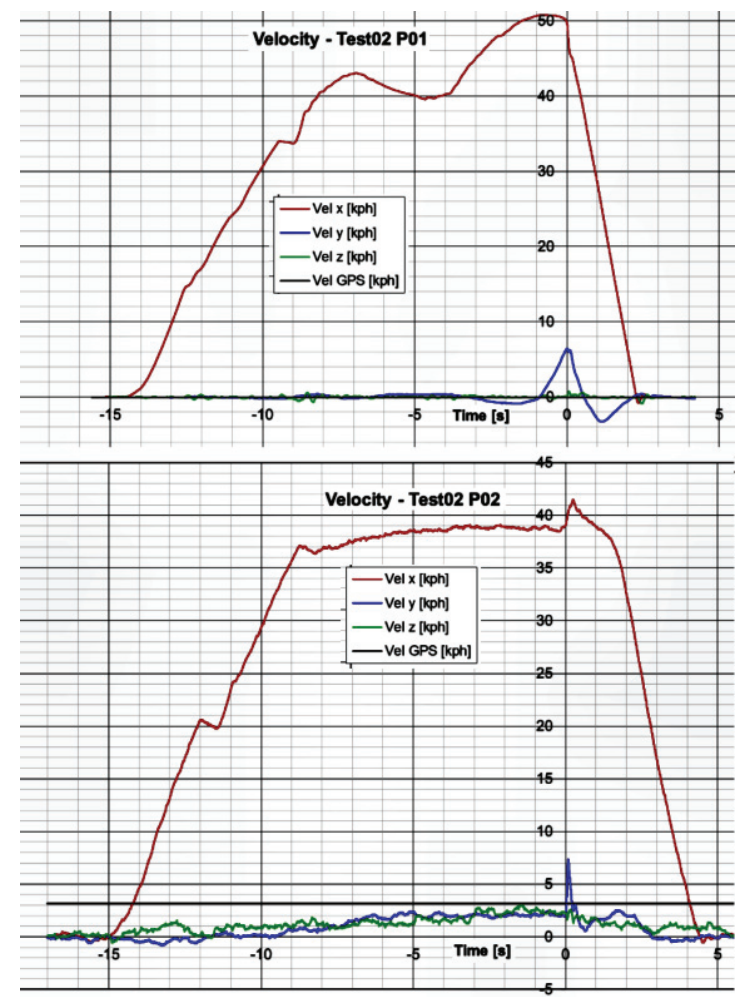

Fig.9. Velocities and GPS speeds of the cars involved in the second collision test

\footnotetext{
${ }^{*}$ Corresponding author: inicu@unitbv.ro
} 


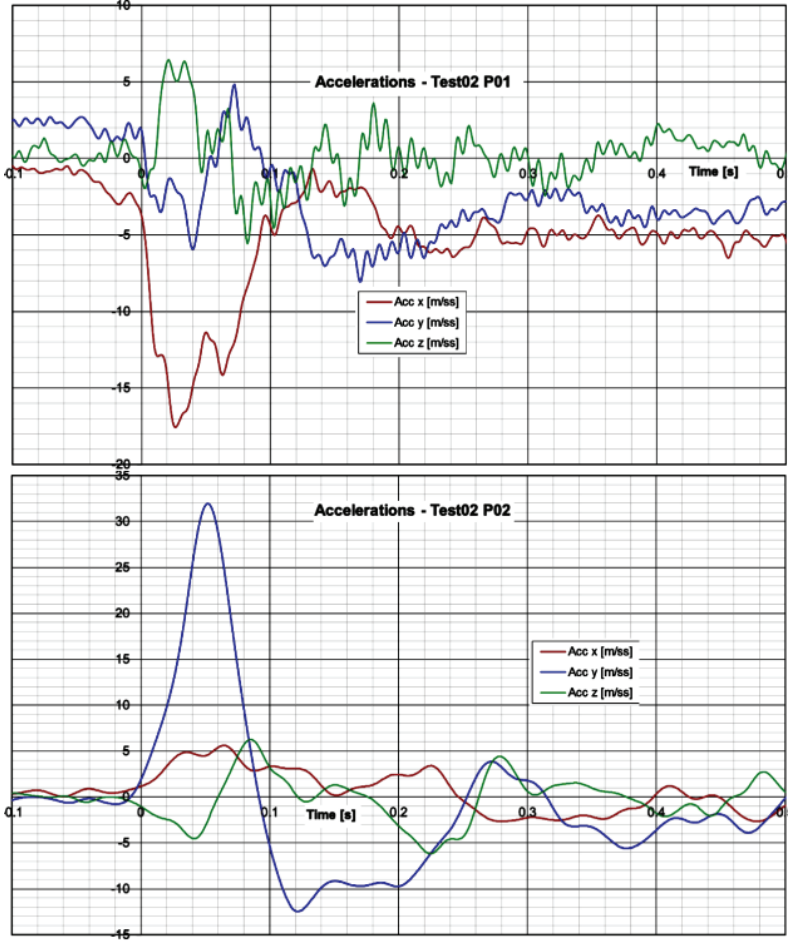

Fig.10. Accelerations of the cars involved in the second collision test

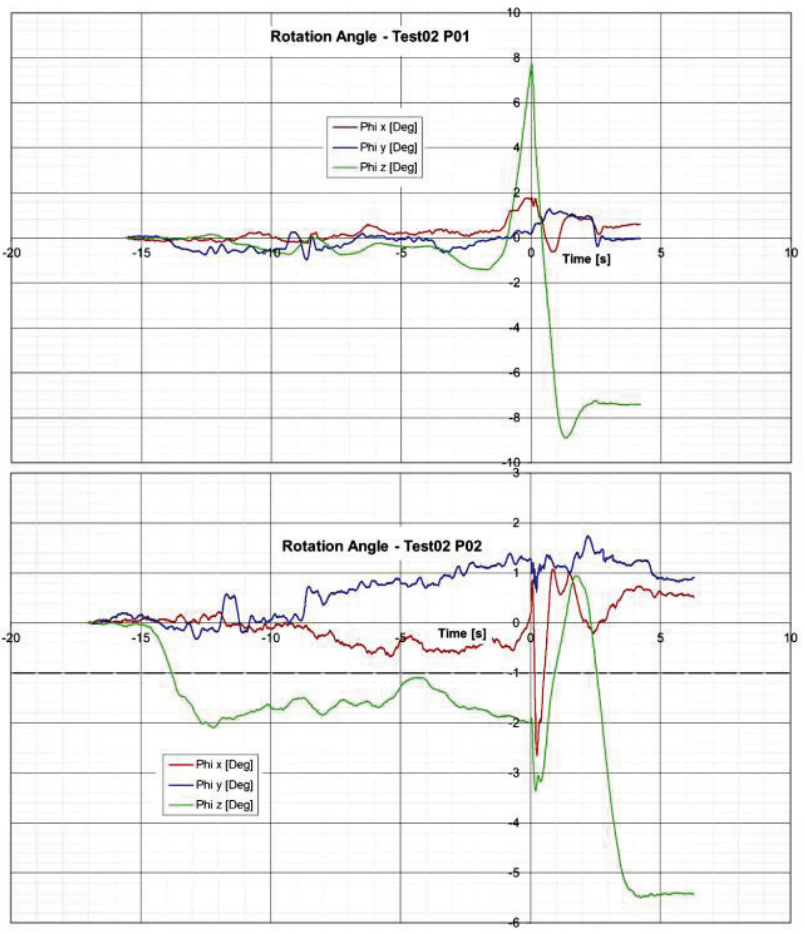

Fig.11. Rotation angles of the cars involved in the second collision test.

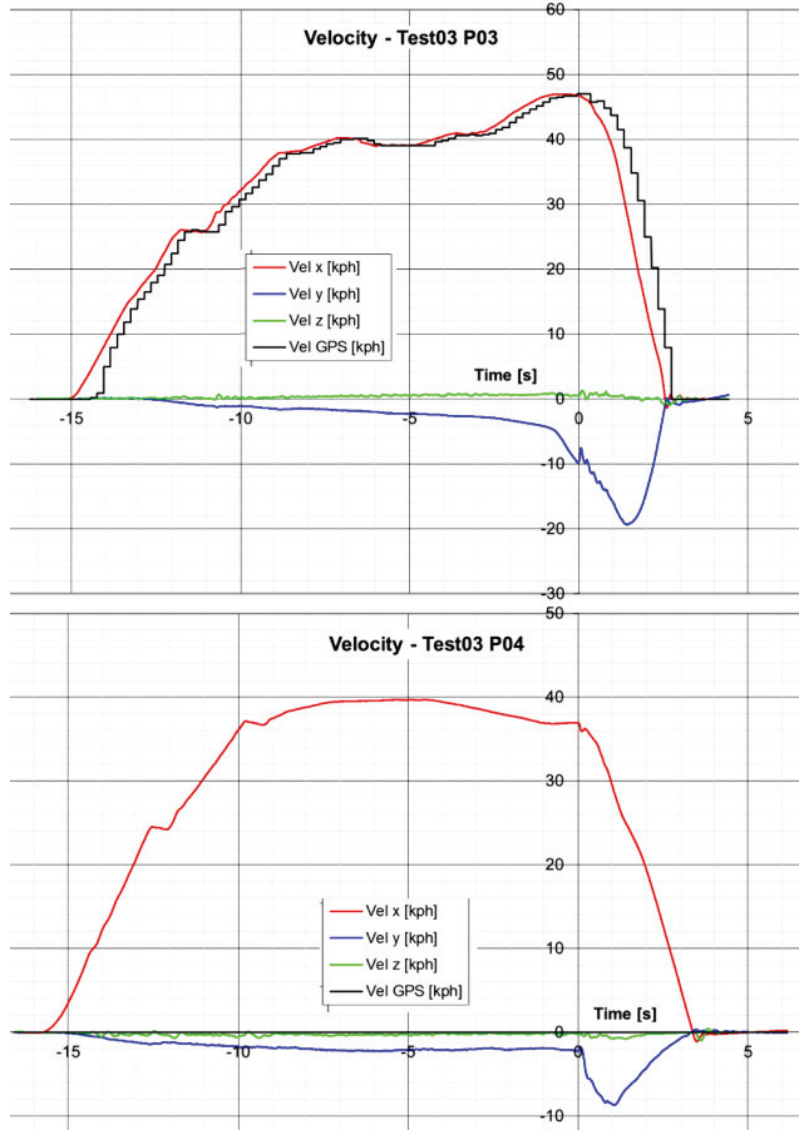

Fig.12. Velocities and GPS speeds of the cars involved in the third collision test.

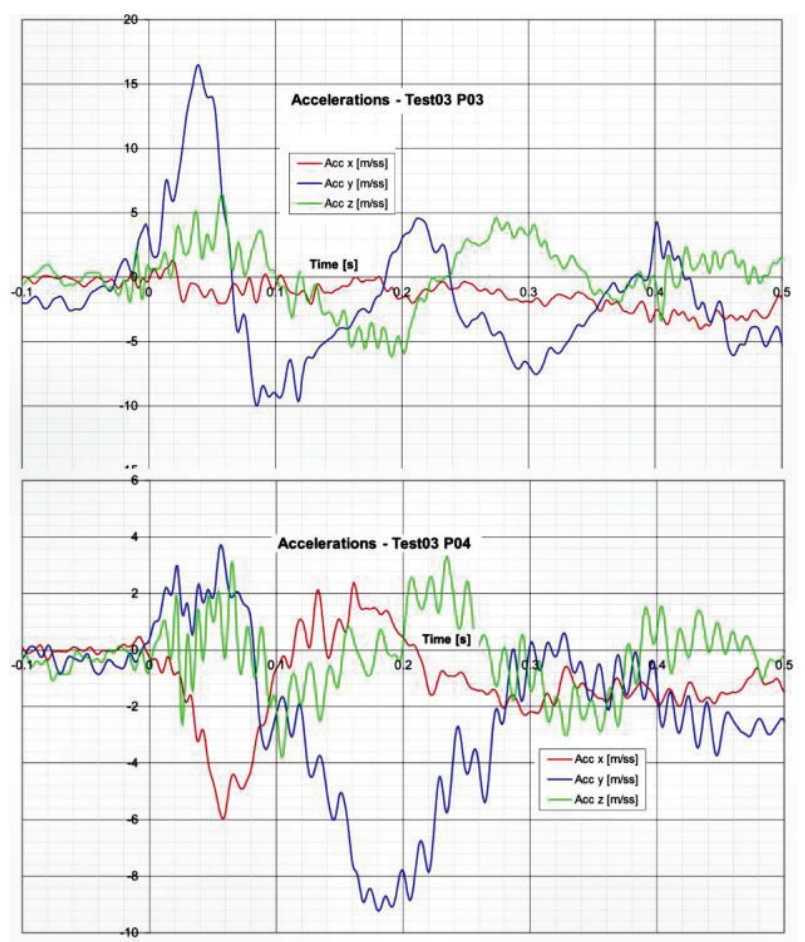

Fig.13. Accelerations of the cars involved in the third collision test.

\footnotetext{
$\overline{{ }^{*} \text { Corresponding author: inicu@unitbv.ro }}$
} 


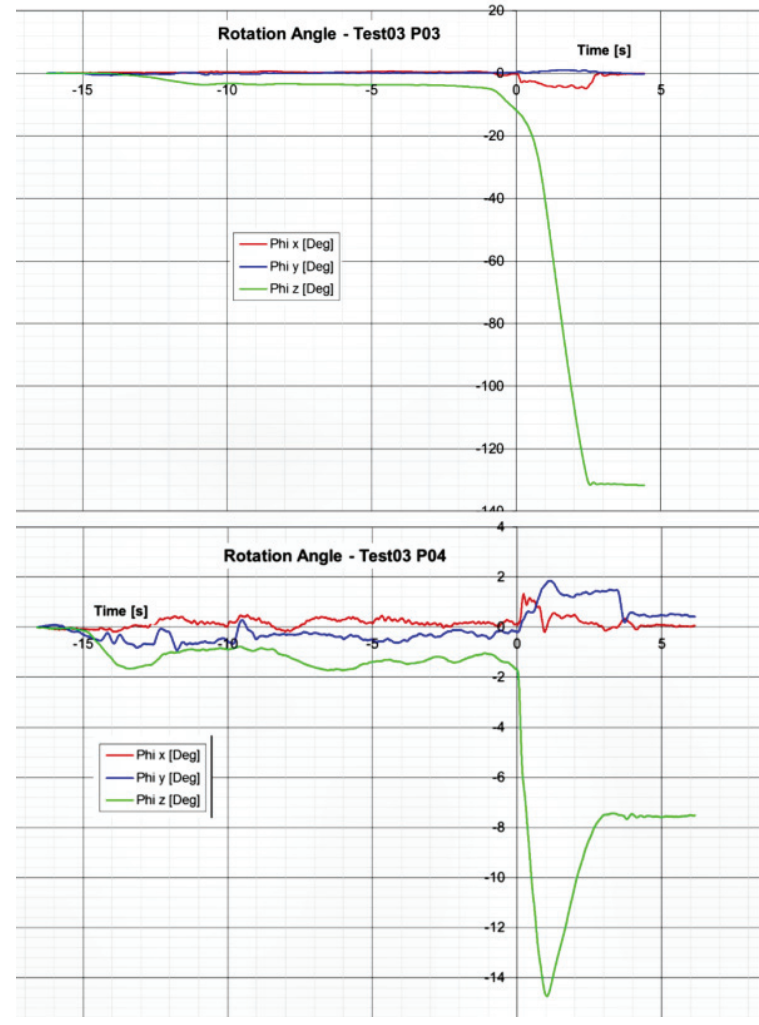

Fig.14. Rotation angles of the cars involved in the third collision test.
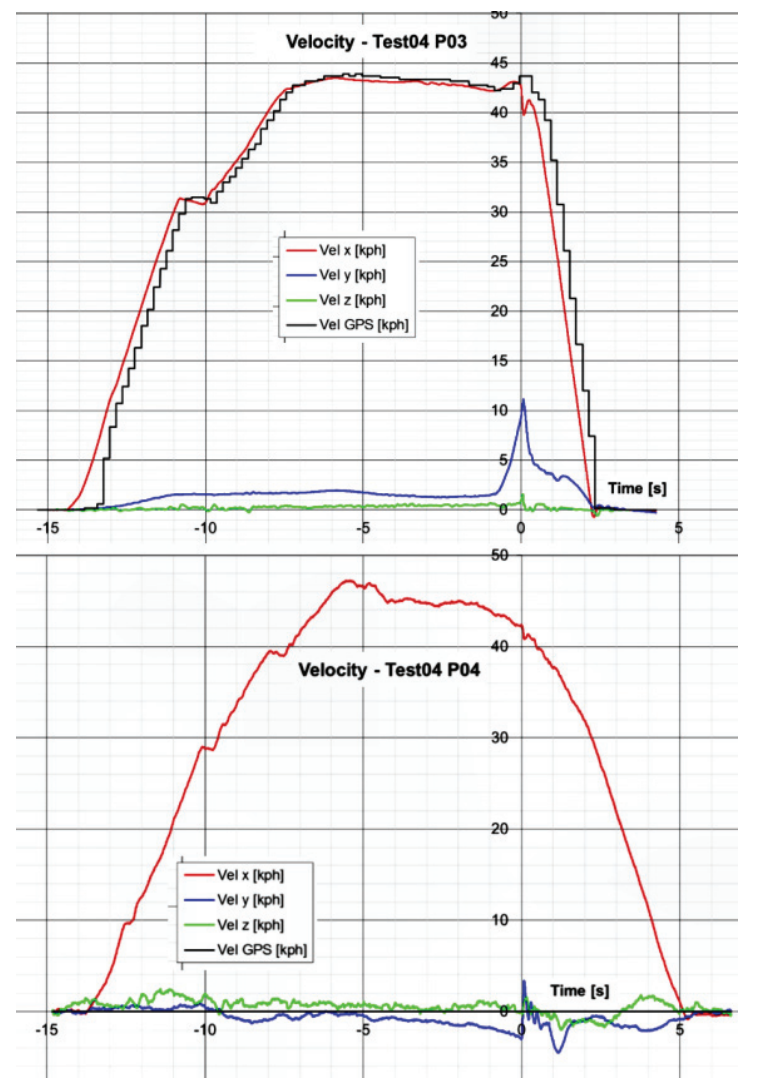

Fig.15. Velocities and GPS speeds of the cars involved in the fourth collision test.

\footnotetext{
* Corresponding author: inicu@unitbv.ro
}

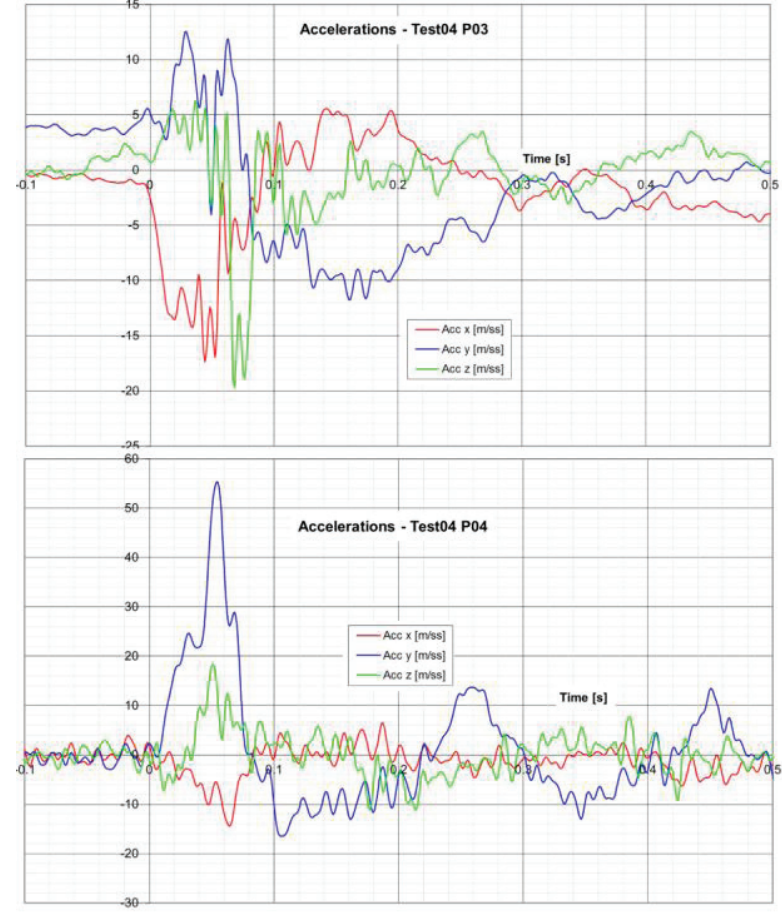

Fig.16. Accelerations of the cars involved in the fourth collision test.

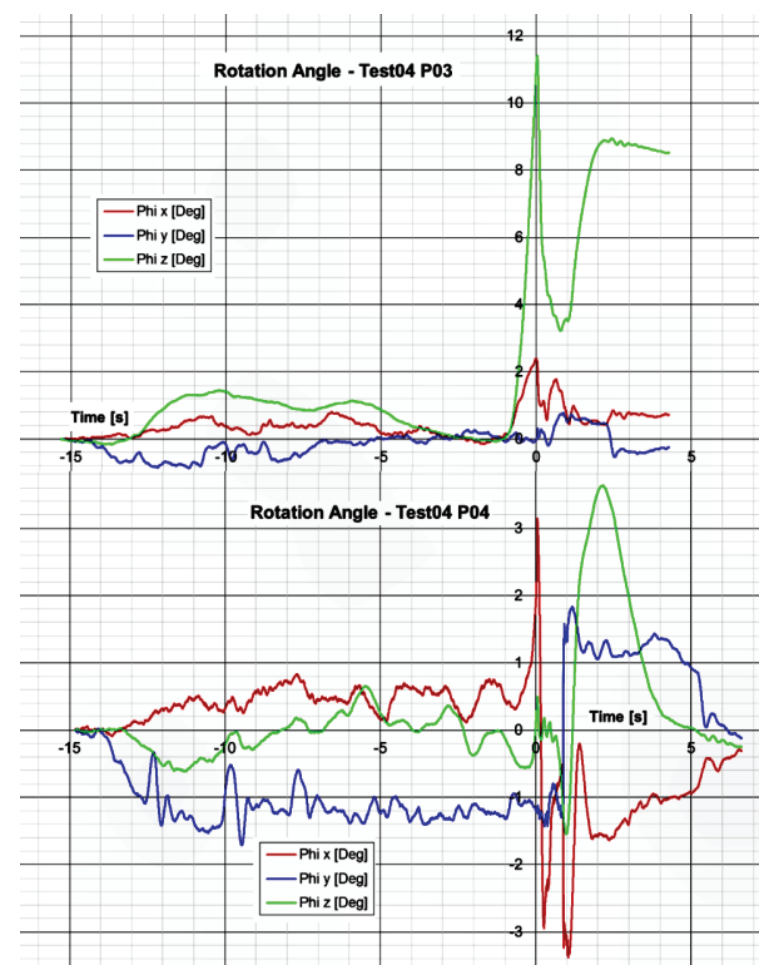

Fig.17. Rotation angles of the cars involved in the fourth collision test.

\section{Conclusions}

The novelty of the paper are the comparisons of data set from two cars involved in each of four experimental crashes. Another novelty consists in possibilities to analyze the influences of the crashes parameter over both 
cars involved damages.

The data obtained are highly reliable given by the quality of the equipment used (N. Ispas, M. Nastasoiu [5]).

Using for each lane change collision case the experimental obtained data, we can write the followers main conclusions:

\subsection{First crash test:}

1. Cars crash was at low collision relative speed (5.9 $\mathrm{km} / \mathrm{h})$;

2. In the hypothesis of the relative speed between the two cars and the similarity with highway traffic, the collision was caused by the car running on the higher speed lane:

3. For the P01 (the impactor car), a maximum acceleration of $23 \mathrm{~m} / \mathrm{s}^{2}$ is recorded in the $Y$ (transverse) direction, and for the other car the maximum acceleration value is $-12 \mathrm{~m} / \mathrm{s}^{2}$ recorded along the $X$ axis (longitudinal);

4. The maximum rotation angle for the P01 was -11 degrees around the $Z$ axis and for the P02 the maximum angle was - 8 degrees around the same $Z$ axis.

\subsection{Second crash test:}

1. Cars crash was at collision relative speed (11.4 $\mathrm{km} / \mathrm{h})$;

2. In the hypothesis of the relative speed between the two cars and the similarity with highway traffic, the collision was caused by the car running on the lower speed lane:

3. For the P01 (the impactor car), a maximum acceleration of $-17,5 \mathrm{~m} / \mathrm{s}^{2}$ is recorded in the $X$ axis (longitudinal) and for the other car the maximum acceleration value is $-32 \mathrm{~m} / \mathrm{s}^{2}$ recorded along the $Z$ axis;

4. The maximum rotation angle for the P01 was -9 degrees around the $Z$ axis and for the P02 the maximum angle was -5.5 degrees around the same $Z$ axis.

\subsection{Third crash test:}

1. Cars crash was at collision relative speed of 10.1 $\mathrm{km} / \mathrm{h}$;
2. In the hypothesis of the relative speed between the two cars and the similarity with highway traffic, the colision was caused by the car running on the higher speed lane;

3. For the P03 (the impactor car), a maximum acceleration of $16.5 \mathrm{~m} / \mathrm{s}^{2}$ is recorded in the $Y$ (transverse) direction, and for the other car the maximum acceleration value is $-8 \mathrm{~m} / \mathrm{s}^{2}$ recorded along the $Y$ axis;

4. The maximum rotation angle for the P03 was -130 degrees around the $Z$ axis and for the P02 the maximum angle was -15 degrees around the same $Z$ axis.

\subsection{Fourth crash test:}

1. Cars crash was at low collision relative speed (1.2 $\mathrm{km} / \mathrm{h})$;

2. In the hypothesis of the relative speed between the two cars and the similarity with highway traffic, the collision was caused by the car running on the lower speed lane:

3. For the P03 (the impactor car), a maximum acceleration of $-19 \mathrm{~m} / \mathrm{s}^{2}$ is recorded in the $Z$ direction, and for the other car the maximum acceleration value is $55 \mathrm{~m} / \mathrm{s}^{2}$ recorded along the $Y$ axis;

4. The maximum rotation angle for the P03 was -11.5 degrees around the $Z$ axis and for the P04the maximum angle was 4 degrees around the same $Z$ axis.

\section{References}

[1] U.S. Department of Transportation, National Highway Traffic Safety Administration "Analysis of Lane Change Crashes", Report, 52 p,DOT-VNTSC-NHTSA-02-03, 2003.

[2] N. Ispas and M. Năstăsoiu "Crash Tests and the Loads over Driver Head in Different Side Impact Cases", Current Solutions in Mechanical Engineering pp 181-186, 2016

[3] N. Ispas and M. Năstăsoiu "A Study Concerning the Loads Over Drivers Heads in the Cases of Cars Crashes with Involved Cars of the Same or Different Generation Proceedings of the European Automotive Congress EAEC-ESFA", 2015 Springer pp 325-336.

[4] Jan van der Sluis, "Vehicle compatibility in car-to-car collisions," Literature review in the framework of the European research project "Improvement of crash compatibility between cars", Workpackage, SWOV Institute for Road Safety Research, The Netherlands. Report, 2000.

[5] N. Ispas, M. Nastasoiu "Cars Crashes with Cars of Same or Different Generation - Occupant's Loads, Timings and Acceleration's Effects", $12^{\text {th }}$ International Congress of Automotive and Transport Engineering (CONAT) Location: Brasov, 2001

\footnotetext{
*Corresponding author: inicu@unitbv.ro
} 